\title{
USO DA TERRA E OCORRÊNCIA DE LAGOAS ENTRE A FAZENDA SANTA MARIA E PORTO DO CAMPO NO RIO SEPOTUBA-MT
}

\author{
EvanilRocha $^{(\mathrm{a})}$ Célia Alvesde Souza $^{(\mathrm{b})}$;Cristiane da Silva Lima ${ }^{(\mathrm{c})} ;$ Vanila Soares Prudêncio $^{(\mathrm{d})}$ \\ ${ }^{(a)}$ Departamento de Geografia da Universidade do Estado de Mato Grosso (UNEMAT) E- \\ mail:evanilmt030@hotmail.com \\ (b) Professora do Departamento de Geografia da UNEMAT. E-mail:celiaalvesgeo@globo.com

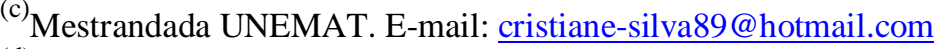

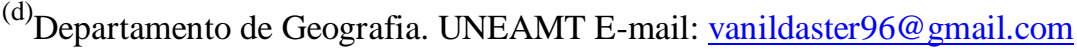

\section{EIXO: BACIAS HIDROGRÁFICAS E RECURSOS HÍDRICOS: ANALISE, PLANEJAMENTO E GESTÃO}

\begin{abstract}
Resumo
O estudo teve como objetivo verificar as mudanças temporais sobre o uso da terra e a ocorrência de lagoas no corredor fluvial do rio Sepotuba entre a fazenda Santa Maria e Porto do Campo. Na confecção os mapas usou imagem de satélite e Sistema de Informações Geográfico (GIS / SIG) por softwareArcGis 9.3.O corredor fluvial do rio Sepotuba entre a fazenda Santa Maria e Porto do Campo passou por várias alterações a cobertura vegetal em 1986 era de $46.349 \mathrm{~km}^{2}$, com desmatamento foi reduzindo para $6.580 \mathrm{~km}^{2}$. A planície de inundação possuía $32.315 \mathrm{~km}^{2} \mathrm{em}$ 1986, com a introdução de pastagem reduziu para $18,322 \mathrm{~km}^{2}$. Varias lagoas desapareceu, a maioria reduziu a área e surgiu 4 lagoas.
\end{abstract}

Palavra Chave:Uso da terra, mudanças temporais, lagoas.

\section{Introdução}

De acordo com Cunha e Guerra (2004), as bacias hidrográficas integram uma visão de conjunto do comportamento das condições naturais e das atividades humanas nelas desenvolvidas. Mudanças significativas em qualquer parte dessa unidade podem gerar alterações, tais como os impactos à jusante.

A bacia hidrográfica Rio Sepotubaocupa uma área de 984.450,51 representa cerca de 1\% da área do estado do Matogrosso, sendo um dos principais canais de escoamento para o Rio Paraguai, com o processo de uso e ocupação na bacia ao longo do tempo pode ocorrer alteração na dinâmica fluvial do rio(SERIGATTO, 2006).

As transformações ocorridas ao longo do espaço e do tempo na bacia hidrográfica são influenciadas pela dinâmica natural ou pelas atividades humanas desenvolvidas na região, a ocupação da terra pode alterar as condições naturais da bacia. Esse processo acontece, em um primeiro momento, por meio da retirada da vegetação, deixando o solo exposto e, em seguida, pela introdução de atividades agropecuárias (SILVA, 2009).

O estudo compõem um projeto maior, que objetiva avaliar o uso da terra e o aporte de sedimentos das bacias contribuintes do rio Paraguai, trazendo para a análise regional sobreas alterações no uso da 
terra e suas consequências. Deve considerar a importância das lagoas permanentes e temporários para diversidade de habitats, que desempenha papel ecológico, econômico e social,

Devido à importância da água no tempo e no espaço, o homem começou a modificar o ambiente natural. Nos últimos anos, políticas voltadas para a ocupação, principalmente com a prática agropecuária, têm gerado mudanças nas condições naturais. Neste contexto, os recursos hídricos têm sido os mais afetados, haja vista serem os rios os componentes mais sensíveis da paisagem, tendo respostas rápidas às perturbações sofridas na bacia hidrográfica e no próprio canal do sistema de drenagem (RITELLA, 2013).

O estudo teve como objetivo verificar as mudanças temporais sobre o uso da terra e a ocorrência de lagoas no corredor fluvial do rio Sepotuba entre a fazenda Santa Maria e Porto do Campo no município de Cáceres-MT.

\section{Materiais e Métodos}

A área de estudo se localiza na bacia hidrográfica do rio Sepotuba entre a fazenda Santa Maria e Porto do Campo. "Entre "as coordenadas geográficas $15^{\circ} 35^{\prime} 04,77^{\prime}$ a $15^{\circ} 42^{\prime} 34.90 \mathrm{~s}$ "e $57^{\circ} 411^{\prime} 58.73^{\prime}$ e $57^{\circ} 42^{`} 37.18^{\prime \prime}$.

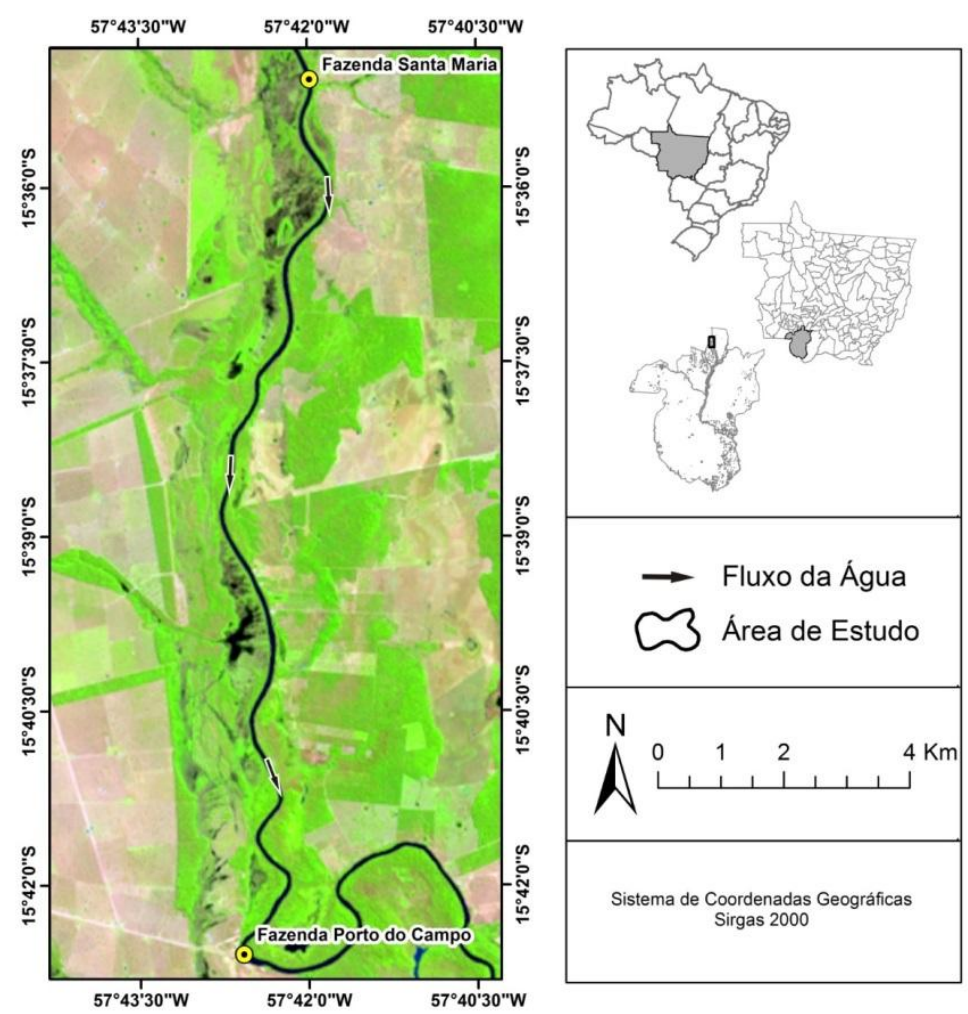

Figura 1- mapa de localização do rio Sepotuba entre a fazenda Santa Maria e Porto do Campo 


\section{Procedimentos metodológicos}

Foram confeccionados mapas de localização e temáticos com utilização de Sistema de Informações Geográfico (GIS / SIG) por softwareArcGis9.3 licenciado, sendo interpretado e projetado os mapas:

- Localização: Foi utilizado imagens de satélite LANDSAT 8 OLI com 30 metros de resolução espacial, posteriormente a imagem passou pela composição de bandas 4, 5 e 6 RGB em falsa cor, logo após redimecionadoraster para 15 metros de resolução pela função Pan Sharpen através da banda 8 (Pan), inserido arquivo vetorial sobre o mesmo delimitando a área de estudo, recortando o raster através da função ExtractbyMask. Confeccionado layout do mapa.

- Temático - espaço temporal: Definido datas para analise espaço temporal, sendo obtidas Imagens/raster dos satélites LandSat 5 TM e LandSat 8 OLI. Criado arquivo vetorial, constituindo classes de análise e classificado por sobre cada feição sobre a área de estudo, posteriormente a vetorização, calculado a área dos polígonos em quilômetros quadrados. O mesmo processo segue-se de forma semelhando a todas as imagens. Confeccionado layout do mapa, seguindo normativas cartográficas.

\section{Resultados e discussão}

As categorias mapeadas foram: cobertura vegetal,planície de inundação e lagoas. A categoria cobertura vegetalcorresponde área de ocorrência de arbórea sob forma de pequenas em pequenos agrupamentos, na área de ocorrência não e influencia pela a cheia do rio Sepotuba.

A categoria planície de inundação corresponde a áreas inundáveis ou sujeitas a inundação,com a ocorrência de acumulações fluviais, diques e cordões fluviais, recoberta por floresta Aluvial ao longo do rio. Esta formação florestal ribeirinha é diversificada, sendo que suas principais características variam de acordo com sua localização na formação aluvial. São vegetações de pequeno porte, adaptáveis ao encharcamento do solo durante o período das cheias.

A categoria planície de inundação corresponde à área com inundação permanente ou temporáriarecoberto por estrato graminosoentremeado de espécies arbustiva de pequeno porte. A planície de inundação é também, chamada de terraço, várzea, leito maior entre outros (GUERRA E GUERRA 2008 P. 494).

O estudo espaço temporal mostrou alteração na cobertura vegetal nas categorias analisadas, com retirada da vegetação e introdução de pastagem. Várias lagoas deixaram de existir possivelmente foram colmatadas, devido o processo intenso de sedimentação no baixo curso, quatro novas lagoas surgiu (Figura 2). 


$\begin{aligned} & \text { XVII Simpósio Brasileiro } \\ & \text { de Geografia Física Aplicada }\end{aligned}$
$\begin{aligned} & \text { I Congresso Nacional } \\ & \text { de Geografia Física }\end{aligned}$

A presença de lagoas é comum em planícies em virtude do lençol freático sub-afloramento e dos embaciamentos que são encontrados na planície. Em 1986 existiam 16 lagoas. No mapeamento de 2016 registrouo desaparecimento de12 Lagoas, surgimento de apenas 4 novas lagoas e redução da área das lagoas.

A categoria cobertura vegetal possuía a área de $46,349 \mathrm{~km}^{2}$ em 1986 , reduziu para $6,580 \mathrm{~km}^{2}$. A planície de inundação foi ocupada pela atividade pecuária em 1986 sua aérea era de $32,315772 \mathrm{~km}^{2}$ e passou para $18,322156 \mathrm{~km}^{2}$.
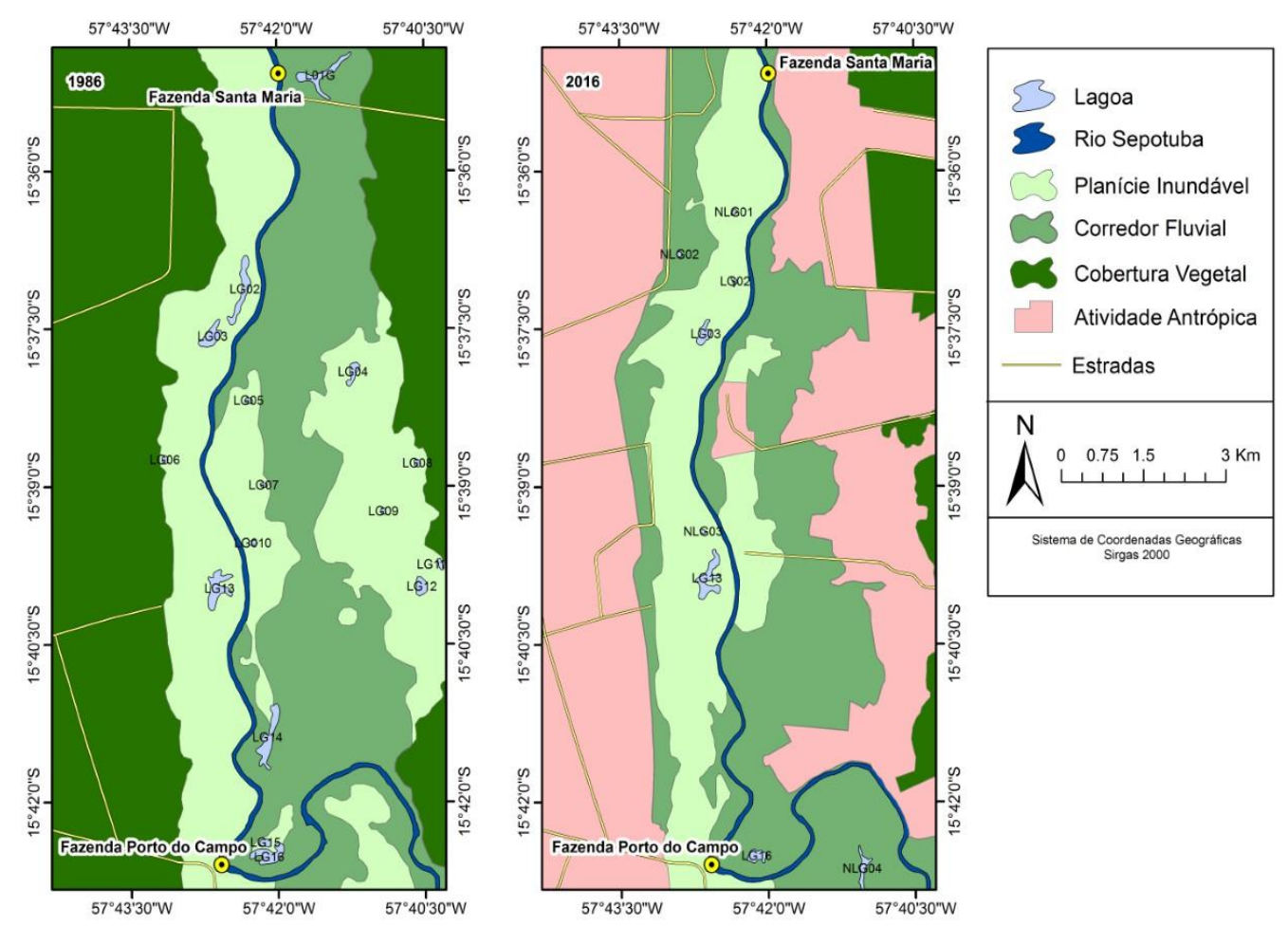

Figura-02 mapa das variações das feições morfológicas entre a fazenda Santa Maria e Porto do Campo.

\section{Considerações Finais}

A área no baixo curso do rio Sepotuba no passou por várias alterações nas categorias mapeadas a vegetação foi retira a implantação de pastagem, ocupando área de $51,60942 \mathrm{~km}^{2}$. Várias lagoas desapareceram, a maioria reduziu a área e surgiu 4 lagoas.

\section{Referências Bibliográficas}

CARVALHO, N.O.Hidrossedimentologiaprática. Rio de Janeiro: CPRM, 1994.

CUNHA, GUERRA; Bacias hidrográficas. Geomorfologia do Brasil. $5^{\circ}$ ed.- Rio de Janeiro: Bertrand Brasil, 2009. 233p.

CUNHA, S.B. da e GUERRA, A.J.T. Degradação Ambiental. In: GUERRA, A.J.T. e CUNHA, S.B. da.(org.). Geomorfologia e Meio Ambiente. Rio de Janeiro. Bertrand Brasil. Capítulo 7, 2004. 
FERNANDEZ, O. V. Q; Mudanças no canal fluvial do Rio Paraná e processos de erosão nas margens: Região de Porto Rico, PR.Dissertação de Mestrado,UNESP, Instituto de Geociências e Ciências Naturais. Rio Claro. 1990. 85 p.

GUERRA, A. T.; GUERRA, A. J. NOVO DICIONARIO - Geológico Geomorfológico. 6 ed. Rio de Janeiro: Bertand Brasil, 2008. 79, 349, 233 e 337p.

GUERRA, A.T.; GUERRA, A.J. (Org.). Novo dicionário Geológico-Geomorfológico. 6 6aed-Rio de Janeiro Bertrand Brasil,2008.79- 349p.

RITELA A., CABRAL I. L. L., SOUZA C. A. Disponibilidade de água e uso da terra na bacia hidrográfica do rio Aguapeí - Mato Grosso/Brasil. ENCICLOPÉDIA BIOSFERA, Centro Científico Conhecer - Goiânia, v.9, n.17; p. 3358-3385. 2013.

SERIGATTO, MARIA, E. Delimitação Automática das áreas de preservação permanente e identificação dos conflitos de uso do terreno da Bacia Hidrográfica rio SEPOTUBA-MT. Viçosa: UFV. 2006.

SILVA, L. N. P. da. Bacia hidrográfica do córrego das Pitas, MT: dinâmica fluvial e o processo de ocupação, como proposta de gestão dos recursos hídricos. 2009. Dissertação (Mestrado em Ciências Ambientais). Programa de Pós-Graduação em Ciências Ambientais, Universidade do Estado do Mato Grosso, UNEMAT, Cáceres, MT, 2009.4 